\title{
Pathologic features of cryopreserved aortic allograft implanted in the active infection
}

\author{
Akitoshi Yamada, MD, ${ }^{a}$ Kenji Okada, MD, ${ }^{a}$ Rei Takahashi, MD, ${ }^{b}$ and Yutaka Okita, MD, ${ }^{a}$ Kobe and Kyoto, Japan
}

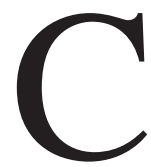

ryopreserved aortic allografts are believed to be more resistant to infectious circumstances than are synthetic grafts. However, their tolerance against infection remains unclear despite, good clinical outcomes. Few pathologic findings of cryopreserved aortic allografts implanted in active infectious sites have been reported in the literature. ${ }^{1} \mathrm{We}$ report our pathologic findings from a cryopreserved aortic allograft that failed to survive in the active infection site.

\section{Clinical Summary}

A 67-year-old man with a saccular descending thoracic aortic aneurysm (Figure 1, A) underwent endovascular repair with a covered stent (self-expandable Cook-Z stent $30 \mathrm{~mm}+$ UBE woven graft $30 \mathrm{~mm}$; Cook Incorporated, Bloomington, Ind). Although the stent-grafting was successful, the patient was back at our hospital with high-grade fever 3 weeks after the procedure. The white blood cell count was 8800 cells $/ \mu \mathrm{L}$, with a leftward shift. The serum C-reactive protein level was increased $5.4 \mathrm{mg} / \mathrm{dL}$. A blood culture demonstrated growths of Enterococcus faecalis and Enterobacter cloacae. A computed tomographic scan of the chest showed fluid collection with air retention around the stent-graft. Although the cause was unknown, aortoesophageal fistula was confirmed by endoscopy and esophageal fluoroscopy (Figure 1,B).

With the patient under general anesthesia, the esophagus was first resected through a left lateral thoracotomy. The infected stent-graft and the residual aneurysm (T9 through T12) were resected en bloc under partial cardiopulmonary bypass. The cryopreserved aortic allograft was implanted with continuous 4-0 polypropylene running sutures. Despite aggressive postoperative intravenous antibiotic therapy, the patient's circulation collapsed on postoperative day 17 from disruption of the proximal allograft anastomosis. The chest was reopened on emergency basis. The allograft was severely contaminated with purulent discharge and had a pseudoaneurysm at the proximal anastomosis. The allograft was replaced with a polytetrafluoroethylene graft with additional

From the Division of Cardiovascular, Thoracic and Pediatric Surgery, Department of Cardio-Pulmonary and Vascular Medicine, Kobe University

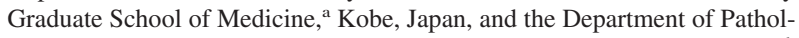
ogy and Tumor Biology, Kyoto University Graduate School of Medicine, ${ }^{\mathrm{b}}$ Kyoto, Japan.

Received for publication Jan 25, 2006; accepted for publication Feb 6, 2006.

Address for reprints: Yutaka Okita, MD, Division of Cardiovascular, Thoracic and Pediatric Surgery, Department of Cardio-Pulmonary and Vascular Medicine, Kobe University Graduate School of Medicine, 7-5-2 Kusunokicho, Chuo-ku, Kobe 650-0017, Japan (E-mail: yokita@med.kobe-u.ac.jp).

J Thorac Cardiovasc Surg 2006;132:203-4

$0022-5223 / \$ 32.00$

Copyright () 2006 by The American Association for Thoracic Surgery

doi:10.1016/j.jtcvs.2006.02.029 omentum wrapping. However, the patient died of sepsis with multiorgan failure on day 21. Tissue culture of the explanted allograft demonstrated $E$ faecalis.

\section{Pathologic Findings}

Vast numbers of cocci and neutrophils were observed in the whole intima of the explanted allograft but not in the media (Figure 2, A). Abscess formations were also detected in both the intima and the adventitia. Staining for $\alpha$-smooth muscle actin to detect smooth muscle cells yielded negative results, even in the media (Figure 2, C), and CD34 staining to detect endothelial cells yielded negative results as well. Smooth muscle cells, bacteria, and even neutrophils were not observed at all in the media, although the elastic fiber framework was preserved intact (Figure 2,B). The boundary lines between the acellular media and the infected intima and adventitia were quite distinct.

\section{Discussion}

Prosthetic vascular graft infection usually results in worsened outcome. Most reported causes of death have been multiorgan failure, sepsis, suture line disruption, and gastrointestinal bleeding. Cryopreserved aortic allografts are widely applied for graft infection because of a potential resistance against infection.

Vogt and colleagues ${ }^{2}$ have suggested that the alleged superior resistance of aortic allografts against infection could be related to their cell viability, which allows improved transfer of antibiotics and immunocompetent cells through the wall into the perigraft space. Aortic allografts may also have an enhanced antimicrobial activity relative to conventional grafts because they are stored in antibiotic solution. ${ }^{3}$

With regard to cellular regeneration, Azuma and associates ${ }^{4}$ demonstrated that endothelial cells of implanted aortic allografts had initial drop in number by the second day and regenerated within 7 days after transplantation. The number of medial smooth muscle cells in transplanted allografts had recovered to the same population as that in native aortas by 2 weeks after transplantation. ${ }^{5}$ However, these experimental studies were done without infection.

In our case, regeneration of the allograft was not detected even on day 17 after implantation. We speculate that the severe infection may have disturbed regeneration of the allograft. Eventually, the allograft was disrupted at the proximal anastomosis. This complication may have been caused by loss of medial smooth muscle cells, which are closely related to the strength of the aortic walls.

The distinct boundary lines between the acellular media and the infected intima and adventitia may be specific findings in this condition. Despite severe infection, the media was free of bacteria and inflammatory cell infiltration, with the elastic fiber framework intact. Although this separation may play a role in resisting infection, the mechanism remains unclear. 


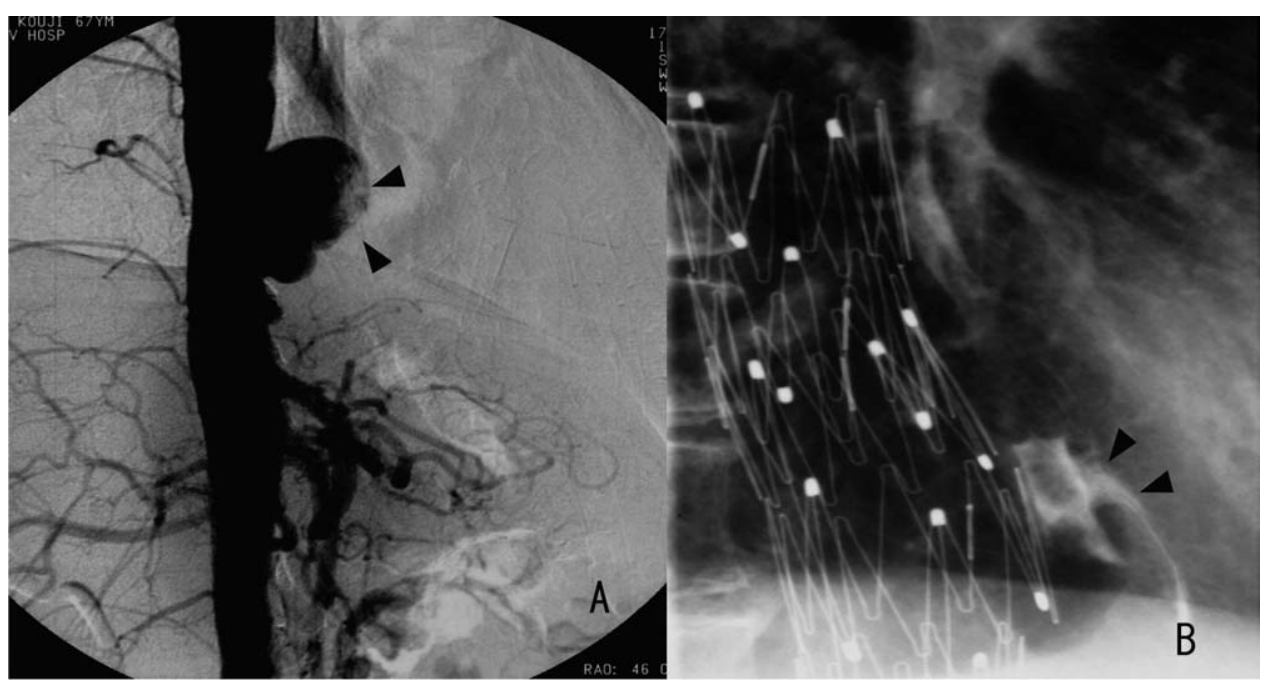

Figure 1. A, Angiography demonstrated saccular descending thoracic aortic aneurysm. B, Esophageal fluoroscopy confirmed aortoesophageal fistula.
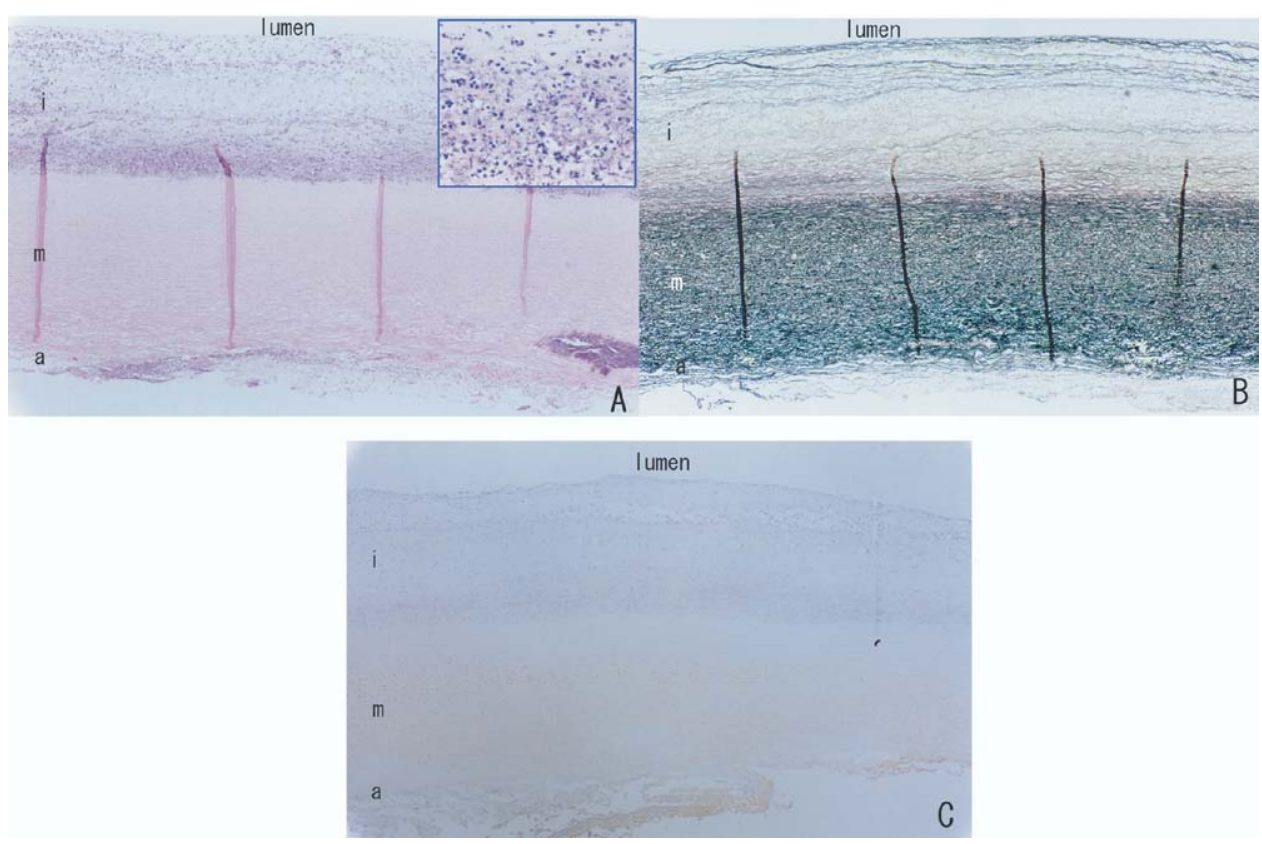

Figure 2. A, Vast numbers of cocci and neutrophils were observed in intima and adventitia, with abscess formation. There were no bacteria, neutrophils, or even smooth muscle cells in media (hematoxylin-eosin stain; original magnifications $\times \mathbf{4 0}$ main, $\times 400$ inset). $i$, intima; $m$, media; $a$, adventitia. B, Elastic fiber framework was preserved intact in media (elastica van Gieson stain; original magnification $\times 40$ ). C, $\alpha-$ Smooth muscle actin stain negative for smooth muscle cells in allograft (original magnification $\times 40$ ).
In conclusion, we have reported the pathologic findings of the cryopreserved aortic allograft implanted in active infection site. Residual active infection may interfere with the survival of the allograft. More pathologic reports with regard to infected allografts could be helpful to elucidate the mechanism of resistance against infection.

\section{References}

1. Schoen FJ, Mitchell RN, Jonas RA. Pathological considerations in cryopreserved allograft heart valves. J Heart Valve Dis. 1995;4 Suppl 1:S72-5.
2. Vogt PR, Brunner-La Rocca HP, Carrel T, von Segesser LK, Ruef C, Debatin J, et al. Cryopreserved arterial allografts in the treatment of major vascular infection: a comparison with conventional surgical techniques. J Thorac Cardiovasc Surg. 1998;116:965-72.

3. Kieffer E, Bahnini A, Koskas F, Ruotolo C, LeBlevec D, Plissonnier D. In situ allograft replacement of infected infrarenal aortic prosthetic grafts: results in forty-three patients. J Vasc Surg. 1993;17: 349-55.

4. Azuma N, Sasajima T, Kubo Y. Immunosuppression with FK506 in rat arterial allografts: fate of allogeneic endothelial cells. J Vasc Surg. 1999;29:694-702.

5. Motomura N, Imakita M, Yutani C, Takamoto S, Kitoh Y, Tsuji T, et al. Histologic modification by cryopreservation in rat aortic allografts. Ann Thorac Surg. 1995;60:168-71. 